\title{
Real Time Scheduling of Nonidentical Multiple Batch Processors with Machine Eligibility Restriction
}

\author{
M. Vimala Rani \\ Vinod Gupta School of Management, \\ Indian Institute of Technology (IIT)-Kharagpur, West Bengal, India. \\ E-mail:vimala@vgsom.iitkgp.ac.in \\ M. Mathirajan \\ Department of Management Studies, \\ Indian Institute of Science (IISc)-Bangalore, India. \\ Corresponding author: msdmathi@iisc.ac.in
}

(Received on September 15, 2021; Accepted on November 6, 2021)

\begin{abstract}
This study addresses a new problem on scheduling of nonidentical multiple diffusion furnaces (NMDF) with machine eligibility restriction (MER) along with important real-life problem characteristics such as multiple and incompatible jobfamilies, different release time, different due-date, non-agreeable release time $\&$ due-date, and occurrences of randomly and dynamically generated real time events (jobs and/or resources related) to minimize total weighted tardiness. Due to the computational difficulty in obtaining an optimal solution for large real-life sized scheduling of NMDF, an alternate solution procedure: heuristic algorithm based on due-date based dispatching rule, called due-date based heuristic algorithm (DDHA) is constructed in this study. Though there has been extensive scheduling research relating to the use of existing dispatching rules in semiconductor manufacturing along with/without new dispatching rules, there is no comparative analysis of all due-date based dispatching rules for real time scheduling (RTS) of NMDF-MER. Hence, this study proposes 20 variants of DDHA, considering various due-date based dispatching rules, for RTS-NMDF-MER and compares their performance. A suitable experimental design is developed and randomly generated 270 instances to represent the research problem considered in this study. From the empirical and statistical analysis carried out in this study, the better performing DDHA(s), for RTS-NMDF-MER, are identified.
\end{abstract}

Keywords- Nonidentical multiple diffusion furnaces, Machine eligibility restriction, Multiple and incompatible job families, Real time scheduling, Due-date based heuristic algorithm.

\section{Introduction}

The importance in scheduling of batch processor (BP) is continually growing due to (a) very lengthy processing time at BP in the respective industry, (b) complex characteristics of the BP problem, and (c) increased applicability across many industry/sector (Mathirajan et al., 2014). A BP can simultaneously process a set of jobs as a batch, subject to the capacity of the BP, with same starting and completion time. Efficient scheduling of BP, considering simultaneously both future arrival of jobs and unanticipated real time events associated with jobs and/or resources at the decision making epoch, is essential to improve the production rate, reduce the work-in-process inventory, due-date compliance, etc. (Pinedo, 2016). Accordingly, this research considers scheduling of diffusion furnaces (DF), batch processors, in semiconductor manufacturing (SM) industry.

The previous studies on scheduling of DF assume that scheduling environment is static (i.e, release time of all jobs are either zero or constant), which rarely holds in practice. Over the period, the researchers relaxed this assumption by considering different release time for each job. Scheduling 
of this type of batch processing problem is called dynamic scheduling in the literature. However, considering only different release time of jobs does not make a scheduling problem dynamic (Baykasoglu and Ozsoydan, 2018). Hence, this study considers the occurrences of various unanticipated real time events related to job(s) [Example: Due-date changes, Job-priority change, Job-cancellation, Hot-job(s), Early/Late arrival of job(s), etc.] and/or resource(s) [Example: Operator illness (during working hour), Shortage of material, Defective material, Tool failure, Machine breakdown, etc.,] along with different release time while scheduling BP. This type of scheduling of BP is called real time scheduling (RTS) of BP.

In all the earlier studies, the researchers assumed that any job can be processed in any available diffusion furnaces. This assumption is not close to real-life situation, particularly in diffusion operation of wafer fabrication stage in semiconductor manufacturing. That is, a set of jobs can process only in a specific diffusion furnace and this is called machine eligibility restriction (MER) in scheduling theory. This important real-life issue is considered here while developing solution methodologies for RTS of nonidentical multiple diffusion furnaces (NMDF).

Among various methodologies available in the literature to address scheduling of diffusion furnaces, heuristic algorithm based on dispatching rule is widely used in SM industry as they (a) are performing reasonably well in a wide range of environments, (b) are relatively easy to implement and understand, (c) need only minimal computational time, and (d) can manage dynamic changes. Though there has been extensive scheduling research relating to the use of existing dispatching rules along with or without new dispatching rules, there is no comparative analysis of all due-date based dispatching rules for real time scheduling (RTS) of NMDF-MER. Hence, this study considers various due-date based dispatching rules such as EDD (Earliest Due-Date), FDD (Flow Due-Date), ODD (Operational Due-Date), MOD (Modified Operational Due-Date), CR (Critical Ratio), MS (Minimal Slack), COVERT (Cost Over Time), ATC (Apparent Tardiness Cost) and/or BATC (Batch Apparent Tardiness Cost), for RTS-NMDF-MER for constructing multiple variants of due-date based heuristic algorithm (DDHA) to optimize due-date based scheduling objective, particularly total weighted tardiness (TWT).

The paper structure is as follows. The closely related review of the study is briefed in Section 2 . Based on the identified research gaps, a new and very closely related real-life research problem on scheduling of NMDF is described along with assumptions in Section 3. The proposed 20 variants of due-date based heuristic algorithm (DDHA) are presented in Section 4. Empirical and statistical evaluations on the performance of the proposed 20 variants of DDHA are discussed in Section 5. Finally, conclusions, managerial implications, limitations, and future research directions are given in Section 6.

\section{A Closely Related Review}

Scheduling is one of the keys to increase productivity in the SM industry. There is a rich amount of reported research studies (Uzsoy et al., 1992; Mathirajan and Sivakumar, 2006b; Zhou et al., 2017) dealing with scheduling in various areas of SM industries. Scheduling in SM can be classified as scheduling in the front end (wafer fabrication and wafer probing processes), and scheduling in the back end (assembly and final testing processes). The front end contributes $90 \%$ of the capital cost, and $80 \%$ of the lead-time of manufacturing (Leachman, 2002). Furthermore, from the technological point of view, the manufacturing process in the front end, particularly wafer fabrication, is more complex (Quadt, 2004). Hence, this study is concerned about scheduling in wafer fabrication. 
The importance of scheduling in wafer fabrication has been increasing steadily over the past few decades (Pirovano et al., 2020). This could be due to the fact that wafer fabrication belongs to the most complex manufacturing systems that exist today (Fowler et al., 2015) and wafer fabrication takes a total of 3 to 15 weeks in comparison with the required overall processing time of 8 to 30 weeks for SM industry (Qi, 2006). Within the various processes in wafer fabrication, the process in the diffusion furnaces $(D F)$ can take up to 10 hours, which is the lengthiest process in comparing with other processes (which may take 1-2h) in the wafer fabrication (Monch et al., 2005). Due to this DF becomes bottleneck. So, we considered the scheduling of DF in this study.

Based on the type of data considered in the study, scheduling research in DF is broadly classified into stochastic (Example: Park and Banerjee, 2011) and deterministic. The deterministic scheduling of DF is considered in most of the studies. The assumption on deterministic is generally accepted by the researchers as well as practitioners because the wafer fabrication shop floor is computerized and due to that any unforeseen situations related to the jobs and/or resources can be observed/noticed easily and suitably the data related to that could be adjusted. So, in this study, we also consider the deterministic scheduling of DF.

Further, the research on deterministic scheduling of DF is grouped based on studies considering diffusion operation (i) along with upstream and/or downstream operation(s) (Example: Pirovano et al., 2020), and (ii) independently, as bottleneck. This study concerns about only the diffusion operations, as this is a bottleneck one due to the requirement of the lengthiest processing time. Moreover, based on the number of diffusion furnaces considered by the researchers, it can be classified into research dealing with (i) single DF (Example: Vimala Rani and Mathirajan, 2016), and (ii) multiple diffusion furnaces (MDF), in parallel. The MDF may be identical (Example: Rocholl et al., 2020) or nonidentical in nature and may or may not have machine eligibility restriction.

The studies on deterministic scheduling of MDF are further classified as static (Example: Mönch and Roob, 2018) and dynamic. The studies on dynamic scheduling can further be grouped into considering (i) only future arrival of jobs, that is jobs are having different release time (Example: Rocholl et al., 2020), and (ii) the occurrences of real time events randomly along with future arrival of jobs. In addition, the deterministic and dynamic scheduling of MDF is further grouped with respect to (w.r.t.) studies considering (a) release time \& due-date as agreeable (Example: Bilyk et al., 2014), and (b) release time \& due-date as non-agreeable.

Finally considering the scheduling objective(s) in deterministic and dynamic scheduling of MDF, the earlier studies are grouped based on completion time-based objectives (Example: Rocholl et al., 2018), and due-date based objectives. Since due-date based scheduling objective is considered in this study, the closely related studies on scheduling of MDF are briefly discussed as follows:

Kurz (2003) considered dynamic scheduling of identical MDF with single job family and agreeable release time and due-date to minimize total weighted tardiness (TWT). They proved that it is not always optimal to load batches fully in the dynamic parallel BP environment while minimizing TWT. Monch et al. (2005), Reichelt and Monch (2006), and Monch et al. (2006) extend the problem configuration considered in Kurz (2003) by including multiple incompatible job families. All these studies proposed ATC (Apparent Tardiness Cost) / BATC (Batch Apparent Tardiness Cost) based heuristic algorithms to minimize TWT. Moreover, Monch et al. (2005), and Reichelt and Monch (2006) implemented genetic algorithm. Further for estimation of the parameters required for 
scheduling, Monch et al. (2006) used the inductive decision trees and neural networks from machine learning.

Malve and Uzsoy (2007), and Chiang et al. (2008) considered the same problem configurations studied by Monch et al. (2005) to minimize Lmax (Maximum Lateness). They proposed EDD (Earliest Due-Date) based heuristic algorithm (EDDHA). Further, they improve the solution by genetic algorithm and local search, respectively.

Cheng et al. (2008), and Chiang et al. (2010) considered the problem configuration and ATC/BATC based heuristic algorithms to minimize TWT, similar to Monch et al. (2005). However, these studies introduced a scheduling approach based on the framework of the Memetic Algorithm. Li et al. (2009), and Li et al. (2010) extend the problem configurations studied by Monch et al. (2005) by including sequence-dependent setup time to minimize TWT. Both the studies proposed ATC / BATC based heuristic algorithms to generate the initial solution for the ant colony optimization algorithm. Kim et al. (2010) extend the problem configuration considered in Monch et al. (2005) by including sequence independent setup time to minimize total tardiness and they modified the EDDHA proposed by Malve and Uzsoy (2007) to get an efficient solution for the problem defined by them.

Bilyk et al. (2014) extend the problem configuration considered in Monch et al. (2005) by including precedence constraints. They proposed mathematical model to minimize TWT. Since the problem is NP-hard, they proposed EDD, and ATC/ BATC based heuristic algorithms to get an efficient solution. Further, they proposed variable neighborhood search scheme and a greedy randomized adaptive search procedure.

Fidelis and Arroyo (2017) considered the same problem configurations studied by Monch et al. (2005). They first proposed the mathematical model and then the meta heuristic: Iterated Greedy and Simulated Annealing to minimize TWT. They used the ATC / BATC based heuristic algorithm proposed by Bilyk et al. (2014) to generate the initial solution for the meta heuristic: Iterated Greedy and Simulated Annealing. Rocholl et al. (2020) extend the problem configuration considered in Monch et al. (2005) by including nonidentical job size. They first proposed mathematical model to minimize TWT and then applied the local search and genetic algorithms for large-sized problem instances.

In addition to the above review on closely related studies on dynamic scheduling of MDF with different due-date based scheduling objectives, there are some analogical studies reported in the literature on dynamic scheduling of BP related to different manufacturing industries. These are briefly reviewed as follows:

Mathirajan and Sivakumar (2006a) focused on the scheduling of batch processor problem observed in steel casting industries. They minimize the TWT on nonidentical multiple batch processors with incompatible job families, nonidentical job sizes, dynamic job arrival. Since the problem is NPhard, they proposed a few greedy heuristic algorithms to get an efficient solution.

A general study on dynamic scheduling of BP problem is addressed by Geiger and Uzsoy (2008). They extended the previously developed genetic learning approach (Geiger et al., 2006) to synthesize new dispatching rules for the single batch processor having dynamic job arrival and incompatible job families to minimize total tardiness. 
Gokhale and Mathirajan (2011) focused on scheduling of single batch processor in the presence of unequal release times, incompatible job families, and nonidentical job sizes, with job splitting to minimize TWT in automobile gear manufacturing industry. They proposed mathematical model and simple greedy heuristic algorithms. In another study, Gokhale and Mathirajan (2012) proposed a heuristic algorithm for scheduling two-stage flow shop in the presence of unequal job release times, non-agreeable job due-dates, incompatible job families to minimize TWT in the automobile gear manufacturing industry.

Cayo and Onal (2020) considered the scheduling problem identified at a manufacturer of commercial building products. They proposed heuristic approach for multiple identical batch processors with precedence constraints, non-zero release date, incompatible job families to minimize total tardiness and $\operatorname{Tmax}\left[\max _{i=1 \ldots N}\left(0\right.\right.$, completion time of job $b_{j}-$ due date of job $\left.\left.b_{j}\right)\right]$. Emde et al. (2020) investigated the problem of scheduling single crane in an automated storage and retrieval system encountered at a major German machine manufacturer. They develop a novel exact algorithm based on branch $\&$ benders cut for scheduling a single batch processor with incompatible job families and precedence relation to minimize $\operatorname{Lmax}\left[\max _{i=1 . . . N}\left(\right.\right.$ completion time of job $b_{j}$ due date of $\left.\left.j o b_{j}\right)\right]$.

From the above briefly presented review on the closely related research, the following research gaps are identified:

(i) It appears that no study addressed the important constraint on machine eligibility restriction (MER) while scheduling multiple (identical/ nonidentical) diffusion furnaces, batch processor. However, the MER issue is addressed in various discrete processor scheduling problems like parallel machines (Ex: Li et al., 2021), unrelated parallel machines (Ex: Yunusoglu and Topaloglu, 2021), flow shop (Ex: Hosseini et al., 2021).

(ii) There is no study considering the occurrences of unanticipated and real time events while developing solution methodologies in scheduling multiple (identical/ nonidentical) diffusion furnaces.

(iii) The earlier reported studies did not include the important problem characteristic on nonagreeable release time \& due-date.

(iv) It seems that there is no study that considered all possible due-date based dispatching rules such as EDD (Earliest Due-Date), FDD (Flow Due-Date), ODD (Operational Due-Date), MOD (Modified Operational Due-Date), CR (Critical Ratio), MS (Minimal Slack), COVERT (Cost Over Time), ATC (Apparent Tardiness Cost) and/or BATC (Batch Apparent Tardiness Cost) for constructing heuristic algorithms to obtain an efficient solution for RTS of multiple (identical/nonidentical) diffusion furnaces.

A new and closely related to real-life scheduling of BP problem in general, particularly Diffusion Furnaces, which is identified based on the research gaps is described in the next section.

\section{Problem Description and Assumption}

In the shop floor, let ' $M$ ' diffusion furnaces exist in parallel with different capacities (i.e. nonidentical multiple diffusion furnaces). Furthermore, some diffusion furnaces are not technically permitted to process certain jobs. In scheduling literature, it is called machine eligibility restriction. Each furnace can process 6 to 12 jobs, as a batch, at a time. Let ' $N$ ' jobs are available for scheduling and each of the jobs is belonging to a different family. Each family has a different processing time. 
However, the processing time required for each of the jobs within a family is same. As the families are incompatible due to the distinct nature of the chemical process in each family, a set of jobs from the different families cannot be batched together. Further, each job has different (a) weight (that is, priority) depending on the importance of the job, (b) due-date, and (c) release time. Moreover, a job that comes early may have a longer due-date than a job that comes late and vice-versa. That is, release time \& due-date are non-agreeable. In addition to all these characteristics/constraints, various unanticipated real time events either associated with the job(s) and/or resource(s) may occur randomly while scheduling the jobs in the nonidentical multiple diffusion furnaces with machine eligibility restriction (NMDF-MER).

At the time of making a decision on scheduling of NMDF-MER, the proposed scheduling algorithms consider all the new arrival of jobs up to the decision-making time epoch along with the occurrences of unanticipated real time events, if any, for updating the crucial inputs on availability of jobs in front of the DF and/or the next available time of DF. Accordingly, the proposed scheduling algorithms are called real time scheduling (RTS) algorithm. The objective of RTS of NMDF-MER is to minimize the TWT, which is critical to avoid important jobs (highest weight job) to be tardy (late). A job's tardiness, $T_{j}$, is defined as $T_{j}=\max \left(0, C_{j}-D_{j}\right)$, where $C T_{j}$ and $\mathrm{DD}_{\mathrm{j}}$ are completion time and due-date of job ' $\mathrm{j}$ ', respectively. A job's weighted tardiness, $\mathrm{WT}_{\mathrm{j}}$ is defined as $\mathrm{WT}_{\mathrm{j}}=\mathrm{W}_{\mathrm{j}} \mathrm{x} \mathrm{T}_{\mathrm{j}}$, where $\mathrm{W}_{\mathrm{j}}$ is weight of the job ' $\mathrm{j}$ '.

As per $\alpha|\beta| \gamma$ representation of Graham et al. (1979), the research problem defined in this paper is represented as "Non-identical multiple diffusion furnaces(NMDF) / machine eligibility restriction (MER), batch, in-compatible job families, dynamic job-arrivals, real time events, nonagreeable release times \& due-dates / Total Weighted Tardiness (TWT)" with the following assumptions for proposing solution methodologies.

(i) All data required for scheduling of NMDF are deterministic and known well in advance.

(ii) All the unanticipated real time events will occur randomly during the scheduling planning period and this is expected to affect the inputs either related to jobs waiting in front of the DF and/or the next available time of DF(s).

(iii) Every job is independent of each other and must pass through the diffusion operation.

(iv) Preemption is not allowed.

(v) Capacity of the diffusion furnace is measured w.r.t. a set of jobs possible to place inside the furnace.

(vi) A set of jobs in a constructed batch for scheduling in a diffusion furnace must be less than or equal to capacity of the corresponding diffusion furnace.

\section{Proposed DDHA for RTS-NMDF-MER}

Vimala Rani and Mathirajan (2016) empirically proved that mathematical model for dynamic scheduling of single DF (DS-SDF) to minimize TWT is computationally intractable. Hence, DRTS of NMDF-MER is also computationally intractable to obtain the optimal solution for real-life sized problems, as DRTS of NMDF-MER subsumes the decision problem on DS-SDF. Due to the computational difficulty in obtaining an optimal solution for large real-life sized RTS-NMDFMER, an alternate solution procedure: heuristic algorithm is planned in this study. Furthermore, the analysis of the literature indicated that simple heuristic algorithms, mostly based on dispatching rule(s), are developed to obtain an efficient solution in semiconductor scheduling (Sarin et al., 2011). 
The popularity of dispatching rule based heuristic algorithms are derived from the fact that they (a) are efficient in a wide range of scheduling problems, (b) are generally easy to understand and computerize, (c) require a very meagre computational time to provide solution, and (d) can deal with dynamic changes easily and quickly. Accordingly, this study proposed due-date based heuristic algorithm (DDHA) for RTS-NMDF-MER problem, which has three interrelated decisions (DF selection, Batch formation, and batch selection), and a solution framework for the same is given in Figure 1. In addition, a step-by-step detail of the proposed DDHA for RTS-NMDF-MER is given here.

Step 1: At the time of deciding a batch (batch selection) for scheduling a DF, (a) if any of the job(s) related unexpected real time event(s) occur then modify corresponding job-data on the work-in-process (WIP), and (b) if any of the resource(s) related unexpected real time event(s) occur then modify the corresponding DF's (say, $\mathrm{DF}_{\mathrm{i}}$ ) available time as $\mathrm{T}_{\mathrm{i}}=\mathrm{T}_{\mathrm{i}}+$ delay time due to resource related unexpected real time events.

Step 2: At the time of deciding a batch for scheduling a DF, capture all the characteristics of the jobs, which are waiting for diffusion operation and the available time of each of the diffusion furnaces (say $\mathrm{T}_{\mathrm{i}}, \mathrm{T}_{\mathrm{i}}>0$, where $\mathrm{i}=1$ to $\mathrm{M}$ and $\mathrm{M}$ indicates number of diffusion furnace).

Step 3: Select the diffusion furnace, which is available earlier.

(i) If a tie occurs in terms of diffusion furnace's available time then select a DF, which has a maximum capacity.

(ii) If a tie occurs in terms of diffusion furnace's available time and maximum capacity then select a DF, which has machine eligibility restriction.

(iii) If a tie occurs in terms of diffusion furnace's available time, maximum capacity and machine eligibility restriction then select a DF arbitrarily.

Step 4: Store the selected DF's available time and its capacity to 'B' \& 'T' respectively.

Step 5: Each of the jobs, which is waiting in front of the selected diffusion furnace, needs to be assigned to a different group based on their family (that is, jobs, which are belonging to same family are in one group).

Step 6: For each of the eligible groups (that is, the group which has an eligible family to process in a selected diffusion furnace), compute Job-Priority-Index for each job using due-date dispatching rule.

Step 7: All the jobs in each of the eligible group needs to be arranged based on the Job-PriorityIndex.

Step 8: For each eligible group, form one temporary batch by selecting ' $\mathrm{B}$ ' jobs from the top. If the number of jobs in any of the temporary batch is not equal to ' $\mathrm{B}$ ' then check the WIP whether the jobs of the same family are coming for diffusion operation in the future. If it is true, then wait for those jobs to form a full batch. Otherwise form a partially filled batch. Now, modify the starting time of the corresponding temporary batch as, max ( $T$, longest release time of all jobs in that temporary batch). 
Step 9: Compute and compare starting time of each temporary batch,

If any temporary batch has a completion time strictly less than the starting time of all other temporary batches then select it and go to Step 12

Else go to Step 10

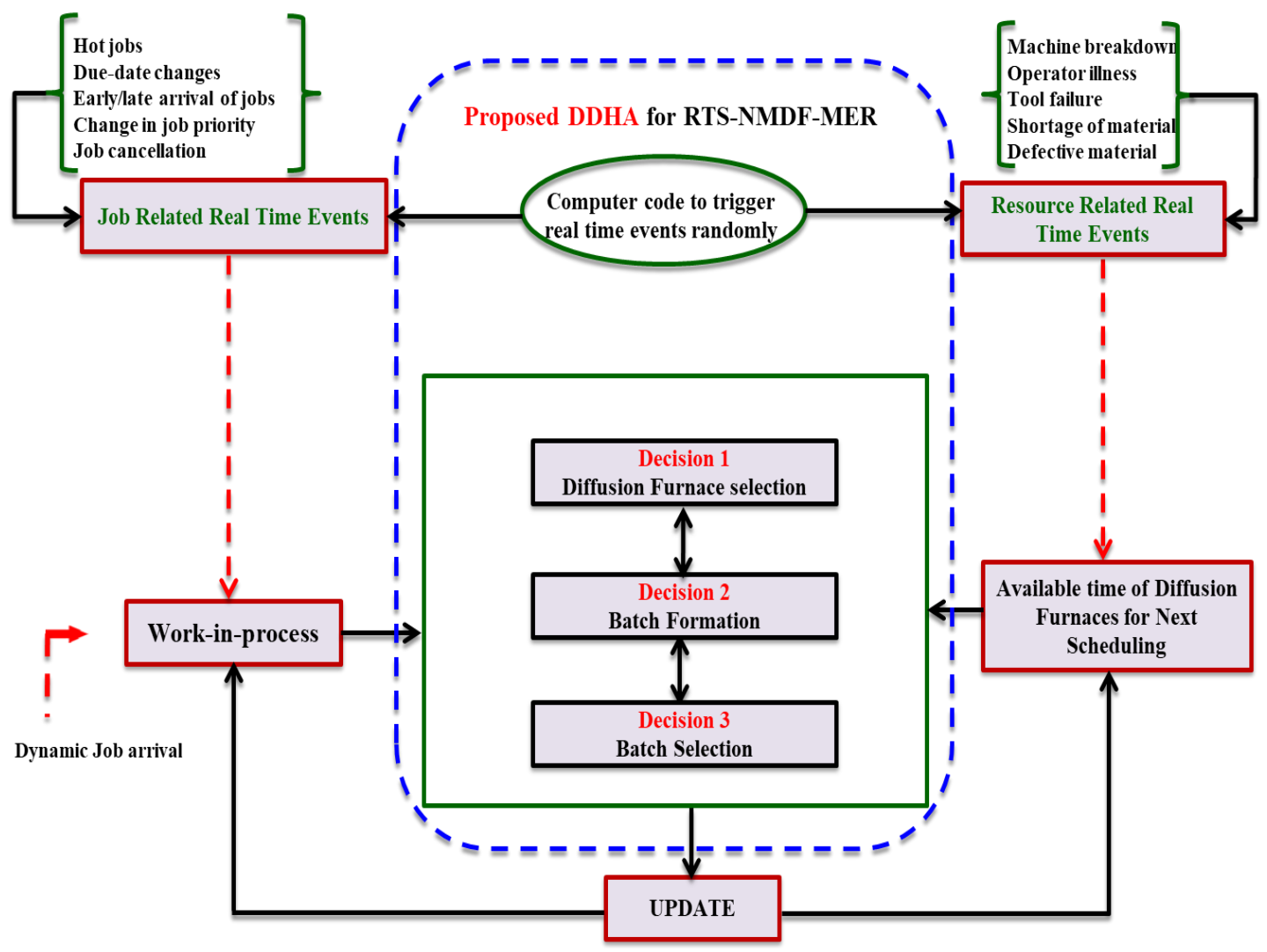

Figure 1. A solution framework for the proposed DDHA for RTS-NMDF-MER.

Step 10: For each temporary batch formed in Step 8, calculate the Batch-Priority-Index using duedate dispatching rule.

Step 11: Select a temporary batch, which has maximum Batch-Priority-Index, by comparing Batch-Priority-Index of each temporary batch.

Step 12: If any of the job-related unexpected real time events occur then modify the corresponding job-data on the work-in-process (WIP) and go to Step 2.

Else if any of the resource related unexpected real time events occur then modify the corresponding DF's $\left(\right.$ say, $\mathrm{DF}_{\mathrm{i}}$ ) available time as $\mathrm{T}_{\mathrm{i}}=\mathrm{T}_{\mathrm{i}}+$ delay time due to resource related unexpected real time events and go to Step 2 .

Else, go to Step 13. 
Step 13: Assign the selected batch to the selected diffusion furnace.

Step 14: Calculate TWT of assigned batch (es).

Step 15: Update the WIP of the jobs by excluding the jobs allocated to the selected DF. Also, update the available time of selected DF as completion time of allocated batch in Step 13.

Step 16: Repeat Step 1 until all the jobs are scheduled.

Considering the above proposed DDHA, this study proposed 20 variants of DDHA by applying different due-date based dispatching rules for computing Job-Priority-Index and Batch-PriorityIndex in the proposed variants of DDHA. Essentially, each of the proposed 20 variants of DDHA for RTS-NMDF-MER differs only in Step 6 (that is, computing Job-Priority-Index for batch formation), Step 7 (that is, jobs arrangement - either in ascending order or descending order of JobPriority-Index), and Step 10 (that is, computing Batch-Priority-Index for batch selection). So, only the modified steps for each of the proposed 20 variants of DDHA for RTS-NMDF-MER are presented in Table 1. All the proposed 20 variants of DDHA for RTS-NMDF-MER are implemented in Turbo C. A walkthrough of the proposed DDHA1 is presented in Annexure 1.

Table 1. Modified steps in proposed 20 variants of DDHA.

\begin{tabular}{|c|c|c|c|}
\hline $\begin{array}{l}\text { Proposed } \\
\text { DDHAs }\end{array}$ & \begin{tabular}{|l} 
Step 6 \\
Batch construction using \\
\end{tabular} & \begin{tabular}{|l|} 
Step 7 \\
Sorting order \\
\end{tabular} & \begin{tabular}{|l|} 
Step 10 \\
Batch selection using \\
\end{tabular} \\
\hline DDHA1 & EDD & Ascending & \multirow{13}{*}{$\begin{array}{l}\text { Weighted Tardiness of Batch (WTB) in Vimala } \\
\text { Rani and Mathirajan (2016) }\end{array}$} \\
\hline DDHA2 & FDD rule in Jayamohan and Rajendran (2000) & Ascending & \\
\hline DDHA3 & ODD rule in Jayamohan and Rajendran (2000) & Ascending & \\
\hline DDHA4 & MOD rule in Jayamohan and Rajendran (2000) & Ascending & \\
\hline DDHA5 & $\mathrm{CR}$ & Ascending & \\
\hline DDHA6 & MS First & Ascending & \\
\hline DDHA7 & COVERT rule in Geiger et al. (2006) & Descending & \\
\hline DDHA8 & ATC rule in Morton and Rachamadugu (1983) & Descending & \\
\hline DDHA9 & ATC rule in Vepsalainen and Morton (1987) & Descending & \\
\hline DDHA10 & \multirow{4}{*}{ ATC rules in Farhad and Laya (2007) } & Descending & \\
\hline DDHA11 & & Descending & \\
\hline DDHA12 & & Descending & \\
\hline DDHA13 & & Descending & \\
\hline DDHA14 & EDD & Ascending & BATC rule in Mehta and Uzsoy (1998) \\
\hline DDHA15 & ATC rule in Balasubramanian et al. (2004) & Descending & BATC rule in Balasubramanian et al. (2004) \\
\hline DDHA16 & ATC rule in Monch et al. (2006) & Descending & BATC rule in Monch et al. (2006) \\
\hline DDHA17 & ATC rule in Li et al. (2010) & Descending & BATC rule in Li et al. (2010) \\
\hline DDHA18 & ATC rule in Li et al. (2010) & Descending & BATC rule in Monch et al. (2006) \\
\hline DDHA19 & ATC rule in Vimala Rani and Mathirajan (2016) & Descending & BATC rule in Monch et al. (2006) \\
\hline DDHA20 & ATC rule in Vimala Rani and Mathirajan (2016) & Descending & $\begin{array}{l}\text { BATC rule in Vimala Rani and Mathirajan } \\
(2016)\end{array}$ \\
\hline
\end{tabular}

\section{Performance Evaluation of Proposed 20 Variants of DDHA for RTS-NMDF- MER}

An estimated optimal procedure (Rardin and Uzsoy, 2001) is used as a benchmark procedure for evaluating the performance of the proposed 20 variants of DDHA for RTS-NMDF-MER. Further, the details on the proposed experimental design, performance measures considered, empirical and statistical analysis performed based on the series of computational experiments towards performance evaluation, are presented in this section. 
Proposed Experimental Design: To generate large-scale suitable test data, an experimental design is proposed considering the parameters: number of diffusion furnaces $(\mathrm{M})$, capacity of diffusion furnaces (B), available time of diffusion furnaces (AT), number of jobs (N), release time of jobs $\left(\mathrm{RT}_{\mathrm{j}}\right)$, due-date of jobs $\left(\mathrm{DD}_{\mathrm{j}}\right)$, number of incompatible job-families (f), processing time of jobfamily $\left(\mathrm{PT}_{\mathrm{f}}\right)$, machine eligibility restriction $\left(\mathrm{M}_{\mathrm{f}}\right)$, and weight of jobs $\left(\mathrm{W}_{\mathrm{j}}\right)$. The values for these parameters are as follows.

This study considers 4 diffusion furnaces: DF1 to DF4 with capacity as 6, 6, 9, and 12 jobs respectively, since in real world the DF capacity is between 6 and 12 jobs. Further, at the beginning of the planning period, each of the diffusion furnaces: DF1 to DF4 is available at $2^{\text {nd }} \mathrm{hrs}, 5^{\text {th }} \mathrm{hrs}, 7^{\text {th }}$ hrs, and $8^{\text {th }}$ hrs respectively. Further, five different job-families are available and that are incompatible with each other. It is also assumed that jobs arrive in front of the DF with $10 \%, 30 \%$, $40 \%, 10 \%$, and $10 \%$ of the time related to job-family $1,2,3,4$, and 5 respectively. That is, this study considers the high probability for the occurrences of jobs related to job-family 3 , which has the processing time of typical diffusion-processing time (i.e. 10hrs). Furthermore, it is assumed that the values related to other parameters: release time of jobs, due-date of jobs, family identification, and weight are drawn from uniform distributions.

Considering the above details, an experimental design, which will be used to generate suitable test data for the problem defined, is developed, and given in Table 2. As per Table 2, this study generates 270 large-scale problem instances to evaluate the performances of the proposed 20 variants of DDHA for RTS-NMDF-MER.

Performance Measures: This study analyzes the solution quality of the proposed 20 variants of DDHA for RTS-NMDF-MER by both empirically and statistically. The details on the performance measures considered for both empirical and statistical performance analysis are given below.

Performance Measure for Empirical Analysis: The standard performance evaluation measure: Average Relative Percentage Deviation (ARPD) is used to analyze the average performance of proposed 20 variants of DDHA. For that, relative percentage deviation (RPD) of each of the proposed 20 variants of DDHA is calculated w.r.t. each problem instance using equation (1) to understand how each of the proposed 20 variants of DDHA is close to the benchmark solution (that is, estimated optimal solution).

$R P D_{i j}=\left(\left(F S_{i j}-B S_{i}\right) / B S_{i}\right) * 100$

where,

$i:$ Problem instance and $i \in[1,270]$

$j: D D H A$ and $j \in[1,20]$

$F S_{i j}$ : Feasible solution obtained from ' $j^{\text {th }}$ ' DDHA for ' $i^{\text {th }}$ ' problem instance

$B S_{i}$ : Benchmark solution for ' $i^{\text {th }}$ ' problem instance

$R P D_{i j}$ : Relative percentage deviation of ' $j^{\text {th }}$ ' DDHA for ' $i^{\text {th }}$ ' problem instance

Further, this study computes, problem configuration wise as well as over the 270 problem instances, Average relative percentage deviation (ARPD) for each of the 20 variants of DDHA as defined in Table 2 using the equation (2).

$A R P D_{j}=\sum_{i=1}^{N} R P D_{i j} / N$ 
where,

$A R P D_{j}:$ Average relative percentage deviation of ' $j^{\text {th }}$ ' DDHA

$N=10$ when $A R P D$ is computed considering problem configuration wise

$N=270$ when ARPD is computed considering entire problem instances

Performance Measures for Statistical Analysis: For performance evaluation using statistical analysis, first we compute descriptive statistics: mean, median, and 95\% confidence interval and then conduct randomized block analysis of variance and Tukey's multiple comparison analysis.

Table 2. A summary of proposed experimental design for NMDF-MER.

\begin{tabular}{|l|l|l|}
\hline Parameters & Number of Levels & Values \\
\hline Number of diffusion furnaces $(\mathrm{M})$ & 1 & 4 \\
\hline DF Capacity $(\mathrm{B})$ & 1 & {$[6,6,9,12]$ for DF1 to DF4 respectively } \\
\hline DF availability Time $(\mathrm{AT})$ & 1 & {$[2,5,7,8]$ for DF1 to DF4 respectively } \\
\hline Number of jobs $(\mathrm{N})$ & 3 & $25,50,100$ \\
\hline Release time of a job $\left(\mathrm{RT}_{\mathrm{j}}\right)$ & 3 & {$[1,8],[1,16],[1,24]$} \\
\hline Due-date of a job $\left(\mathrm{DD}_{\mathrm{j}}\right)$ & 3 & {$[1,40],[1,60],[1,80]$} \\
\hline Number of Family $(\mathrm{f})$ & 1 & {$[1,5]$} \\
\hline $\begin{array}{l}\text { Processing time of a family }\left(\mathrm{PT}_{\mathrm{f}}\right) \text { with probability of job } \\
\text { being in the family ' } \mathrm{f} \text { ' }\end{array}$ & 1 & {$[2,4,10,16,20]$ with the probability of } \\
\hline Machine eligibility restriction $\left(\mathrm{M}_{\mathrm{j}}\right)$ & 1 & {$[0.1,0.3,0.4,0.1,0.1]$ respectively } \\
\hline Weight $\left(\mathrm{W}_{\mathrm{j}}\right)[$ Low, High] & 1 & {$[1,10]$} \\
\hline Number of problem configurations & $3 * 3 * 3 * 1 * 1 * 1=\mathbf{2 7}$ & \\
\hline Number of instances per configuration & 10 & \\
\hline Total problem instances or test instances & $\mathbf{2 7 0}$ & \\
\hline
\end{tabular}

\subsection{Performance Evaluation by Empirical Analysis}

270 test problem instances are generated as per the proposed experimental design in Table 2 by developing a code in Turbo C. Each of the 270 problem instances is solved using each of the proposed 20 variants of DDHA and recorded the 270x20 solutions (that is, TWT values). That is, for each problem instance, 20 feasible solutions are obtained. Due to the brevity of the report, 270 TWT values corresponding to 270 problem instances obtained from each of the proposed 20 variants of DDHA are not given here. Using the 20 feasible solutions obtained for each of the 270 problem instances, an estimated optimal solution is calculated, as per the procedure discussed in Rardin and Uzsoy (2001), for each of the 270 problem instances.

Using equation (1), the 270x20 recorded solution on TWT, and the computed estimated optimal solution for each of the 270 problem instances, the RPD score is computed for each of the problem instances and each of the proposed 20 variants of DDHA. Moreover, for each of the proposed 20 variants of DDHA, using equation (2) and using the computed RPD scores, the ARPD score is computed for each of the problem configurations as defined in Table 2 and presented in Table 3. This study also computes minimum and maximum values of configuration wise ARPD scores and the same are presented in Table 3. Further, using equation 2 and using the computed RPD scores, the average RPD (ARPD) score and standard deviation of RPD score over 270 problem instances are computed for each of the proposed 20 variants of DDHA and presented in Figure 2. 
From Table 3 and Figure 2, this study observed that the proposed due-date based heuristic algorithms: DDHA15 to DDHA20, which has ATC based composite dispatching rule for the two interrelated decisions: constructing the batch and selecting the batch, for RTS-NMDF-MER are relatively outperforming heuristic algorithms [that is, these DDHAs have the solution close to the benchmark solution (that is, estimated optimal solution)] among the 20 variants of DDHA in terms of Average RPD, Standard deviation of RPD, Minimum, and Maximum value of configuration wise ARPD scores. The reasons for the outperforming due-date based heuristic algorithm: DDHA15 to DDHA20 could be due to the fact that these heuristic algorithms compute the job priority as well as the batch priority based on the slack time and it leads to avoiding getting high priority for low priority jobs. Further, the outperforming heuristic algorithms: DDHA15 to DDHA20 for RTS-NMDF-MER endorses one of the main conclusions of the study by Durasevic and Jakobovic (2018).

\subsection{Performance Evaluation by Statistical Analysis}

This study uses SPSS statistical software to understand the relative performance of the proposed 20 variants of DDHA, statistically. First, this study computed descriptive statistics: Mean, median, and $95 \%$ confidence interval using the $(270 \times 20)$ TWT values obtained considering 270 problem instances and 20 variants of DDHA. The computed statistical values are presented in Table 4. It is observed from Table 4 that the proposed due-date based heuristic algorithms: DDHA15 to DDHA20 are relatively better ones in terms of mean, median, and 95\% confidence interval w.r.t. TWT values. This endorsed the observations obtained and presented from the empirical analysis with statistical support.

In addition to the above descriptive statistical analysis, we further carried out a randomized complete block design experiment to statistically analyze the performance of the proposed 20 variants of DDHA. Accordingly, the model of the experiment is as follows.

$$
Y_{i j}=\mu+\alpha_{i}+\beta_{j}+\epsilon_{i j}
$$

Here, $Y_{i, j}$ is a dependent variable (i.e. TWT), $\mu$ is the overall mean; $\alpha_{\mathrm{i}}$ is effect for $i^{\text {th }}$ treatment (i.e. $\mathrm{DDHA}_{\mathrm{i}}, i=1,2, \ldots 20$, it describes how mean for DDHA $\mathrm{i}_{\mathrm{i}}$ differs from overall mean), $\beta_{j}$ is effect for

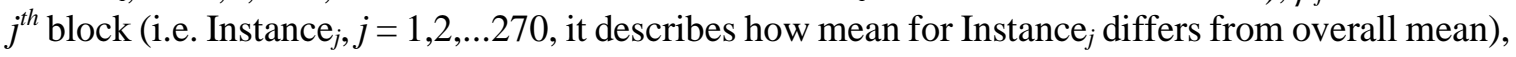
and $\epsilon_{i, j}$ is the random error. With this, the proposed hypothesis of the randomized complete block design experiment is given below.

$\mathrm{H}_{0}$ : There is no treatment effect (that is, the performance of all proposed 20 variants of DDHA are identical).

$\mathrm{H}_{\mathrm{a}}$ : There is a treatment effect (that is, the performance of at least one DDHA is different from others).

The above hypothesis is tested in SPSS by considering a 5\% significance level (that is 95\% confidence interval). With this, Table 5 presents the results of the ANOVA. From the analysis, the null hypothesis is rejected, as the P-values are less than 0.05 , and concluded that at least one proposed DDHA is statistically different from the other proposed DDHAs. To understand further, this study also performed Tukey's multiple comparison analysis $(20 * 19=380$ comparison $)$ to determine which treatment (i.e. DDHA) means are similar and which are different. The hypothesis of the same is given below. 
Rani \& Mathirajan: Real Time Scheduling of Nonidentical Multiple Batch Processors with ...

$\mathrm{H}_{0}$ : There is no difference between $\mathrm{DDHA}_{\mathrm{i}}$ and $\mathrm{DDHA}_{\mathrm{j}}$ in terms of performance.

$\mathrm{H}_{\mathrm{a}}$ : There is a difference between $\mathrm{DDHA}_{\mathrm{i}}$ and $\mathrm{DDHA}_{\mathrm{j}}$ in terms of performance.

Table 3. Performance analysis of the proposed 20 variants of DDHA in comparison with estimated optimal solution.

\begin{tabular}{|c|c|c|c|c|c|c|c|c|c|c|c|c|c|c|c|c|c|c|c|c|c|}
\hline \multirow[b]{2}{*}{$\begin{array}{l}\dot{z} \\
\dot{s}\end{array}$} & \multirow{2}{*}{ 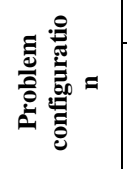 } & \multicolumn{20}{|c|}{ Problem configuration wise ARPD score for each of the proposed 20DDHA in comparison with benchmark solution } \\
\hline & & $\begin{array}{l}\bar{\lambda} \\
\overline{1}\end{array}$ & $\begin{array}{l}\text { 主 } \\
\text { 定 }\end{array}$ & 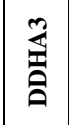 & $\begin{array}{l}\text { 导 } \\
\text { 吾 }\end{array}$ & $\frac{\ln }{\overline{1}}$ & $\begin{array}{l}\bar{b} \\
\overline{\bar{I}} \\
\overline{\mathbf{a}}\end{array}$ & 式 & 赵 & $\vec{i}$ & 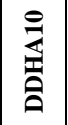 & 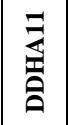 & $\frac{\mathfrak{Z}}{\bar{a}}$ & 离 & 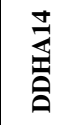 & $\frac{n}{2}$ & 证 & 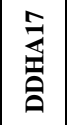 & $\stackrel{\infty}{\leq}$ & $\hat{z}$ & tis \\
\hline 1 & & & & 239 & 239 & 7 & 7 & & 198 & 111 & 84 & 17 & 4 & 17 & 517 & & 9 & 56 & 59 & 0 & 0 \\
\hline 2 & & & 27 & & 827 & 6 & 6 & 6 & & 13 & 9 & 56 & 6 & 56 & 57 & 260 & & 4 & 26 & 26 & 14 \\
\hline 3 & & 33 & 3 & 33 & 33 & 33 & 33 & 396 & 49 & 26 & 328 & 33 & J. & 33 & 144 & 15 & 290 & 55 & 0 & 290 & 107 \\
\hline 4 & & & 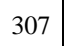 & 307 & 307 & 251 & 51 & & 740 & 736 & 2 & 51 & 255 & 251 & 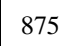 & 62 & 49 & 70 & 49 & 49 & 75 \\
\hline 5 & & & & 220 & 220 & 118 & 18 & & & 321 & 57 & 118 & & 118 & 101 & 281 & & 8 & 24 & 24 & 237 \\
\hline 6 & & & & & 978 & & 4 & & & & & & & & & 1 & & 3 & 66 & 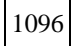 & 166 \\
\hline 7 & & & 2 & 122 & 122 & 120 & 20 & 51 & 313 & 313 & 263 & 120 & 120 & 120 & 111 & 92 & 81 & 44 & . & 81 & 162 \\
\hline 8 & & & & & 12 & 180 & 180 & & & & & 180 & & & & & & & & 39 & 144 \\
\hline 9 & & & & & 29 & 2 & & & & & & & & & & & & & & 5 & 123 \\
\hline 10 & & & & & & $\mid$ & 102 & & & & & 106 & & & & & & & 10 & 11 & 170 \\
\hline 11 & & & 68 & 8 & 1 & & 196 & & & & & 196 & & & & & & & & & 0 \\
\hline 12 & & & 60 & 60 & 2 & 1 & 74 & 2 & & & 674 & 4 & 1 & 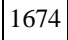 & & & & & & & 12 \\
\hline 13 & & & & & 3 & 321 & 21 & & & & 6 & 21 & 46 & & & & & 12 & & 1 & 200 \\
\hline 14 & & & & & & 648 & & & & & & & & & & & & 50 & קy & & 75 \\
\hline 1 & & & & & & & & & & & & & & & & & & & & & 27 \\
\hline 16 & & & & & & & & & & & & & & & & & & & & & 33 \\
\hline 17 & & 26 & 68 & 1368 & 1368 & 1626 & 1626 & - & 1156 & & 1460 & 1626 & 1460 & 26 & 93 & & & & & 2 & 11 \\
\hline 1 & & & & & & & & & & & & & & & & & & & & & 5 \\
\hline 19 & & & & & & & & & & & & & & & & & & 12 & & 23 & 27 \\
\hline 20 & & & & & & & & & & & & 155 & & & & & & 3 & 7 & & 23 \\
\hline 21 & & & 18 & 1 & 1 & 5 & & & & & & 310 & & & & & & & & 01 & 100 \\
\hline 22 & & & & & 20 & & & & & & & & & & & & & & & & 17 \\
\hline 23 & רסי & & & & 370 & 261 & 263 & 85 & 208 & 230 & 254 & 261 & 254 & 261 & 278 & & 62 & 16 & 37 & & 45 \\
\hline 24 & & & 98 & 1108 & 1108 & 519 & & & 704 & & 2 & 19 & 92 & & 14 & & & & 03 & +1 & 57 \\
\hline 25 & A3,D1 & & & 201 & 201 & . & 194 & & 154 & 101 & 20 & 170 & 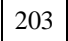 & 193 & 247 & 41 & 36 & 34 & 15 & 10 & 29 \\
\hline 26 & & & & & & 342 & 344 & & 234 & & 326 & 342 & & 342 & & & 137 & 29 & 19 & 43 & 85 \\
\hline 2 & & & 4 & 1 & 1 & 7 & 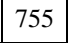 & & 606 & 584 & 767 & 792 & 767 & 792 & 15 & 10 & & & 71 & 71 & 74 \\
\hline & $R P D$ & 3 & 33 & 33 & & & & & 49 & & & & & & & & 15 & 2 & 10 & 10 & 4 \\
\hline & & 1674 & 60 & 2260 & 2260 & 1674 & 1674 & 2465 & 2808 & 2808 & 1674 & 1674 & 1674 & 1674 & 11162 & 1291 & 1096 & 1067 & 1096 & 1096 & 81 \\
\hline
\end{tabular}




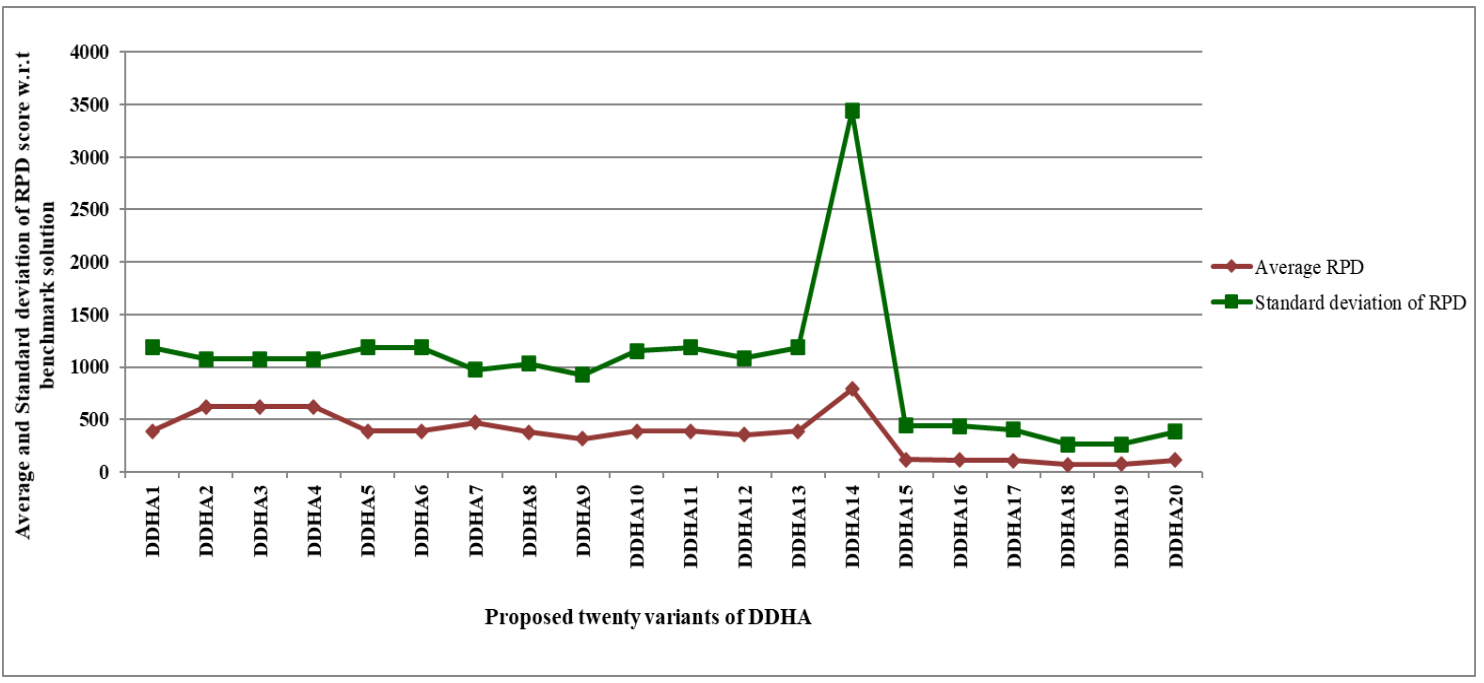

Figure 2. Performance analysis of the proposed 20 variants of DDHA in comparison with estimated optimal solution over 270 problem instances.

Table 4. Descriptive statistics, w.r.t. TWT values, of proposed 20 variants of DDHA.

\begin{tabular}{|c|c|c|c|}
\hline \multirow{2}{*}{ Proposed DDHA } & \multicolumn{3}{|c|}{ Descriptive Statistics w.r.t TWT Values } \\
\cline { 2 - 4 } & Mean & Median & 95\% Confidence Interval \\
\hline DDHA1 & 1487.03 & 467 & $(1237.63,1736.43)$ \\
\hline DDHA2 & 2004.96 & 771.5 & $(1712.39,2297.53)$ \\
\hline DDHA3 & 2004.96 & 771.5 & $(1712.39,2297.53)$ \\
\hline DDHA4 & 2004.96 & 771.5 & $(1237.63,1736.43)$ \\
\hline DDHA5 & 1487.03 & 467 & $(1234.01,1733.92)$ \\
\hline DDHA6 & 1483.96 & 467 & $(1131.63,1567.66)$ \\
\hline DDHA7 & 1487.00 & 647 & $(1041.33,1460.86)$ \\
\hline DDHA8 & 1349.65 & 473 & $(1237.63,1736.43)$ \\
\hline DDHA9 & 1251.10 & 389 & $(1193.77,1694.56)$ \\
\hline DDHA10 & 1445.62 & 420 & $(1237.63,1736.43)$ \\
\hline DDHA11 & 1487.03 & 467 & $(1520.03,2122.33)$ \\
\hline DDHA12 & 1444.16 & 424 & $(565.5,806.75)$ \\
\hline DDHA13 & 1487.03 & 467 & $(611.99,867.2)$ \\
\hline DDHA14 & 1821.18 & 559 & $(534.25,757.5)$ \\
\hline DDHA15 & 686.13 & 236 & $(512.16,722.8)$ \\
\hline DDHA16 & 739.60 & 229.5 & $(530.24,761.11)$ \\
\hline DDHA17 & 645.87 & 235.5 & $(585.46,838.94)$ \\
\hline DDHA18 & 617.48 & 212 & 218.5 \\
\hline DDHA19 & 645.67 & 253.5 & \\
\hline DDHA20 & 712.20 & & \\
\hline & & & \\
\hline & & & \\
\hline
\end{tabular}


Due to the brevity of the paper, Table 6 shows only the P-values of multiple comparisons. Table 6 indicates that the proposed due-date based heuristic algorithms: DDHA15 to DDHA20 are statistically different from other proposed DDHA (i.e. DDHA1 to DDHA14), as the p-values are 0 (which is less than 0.05). In addition, there is no statistically significant difference between DDHA15 to DDHA20, as the p-values are 1 or near to 1 , which is greater than 0.05 . Finally, this study identified 3 homogeneous subsets among the proposed 20 variants of DDHA based on mean as shown in Table 7. The due-date based heuristic algorithms in subset 1 (DDHA15 to DDHA20) are statistically better than subset 2 (DDHA1, DDHA5 to DDHA13), and subset 3 (DDHA2 to DDHA4, DDHA14). Similarly, the due-date based heuristic algorithms in subset 2 are statistically better than subset 3 . Further, there is no statistically significant difference between the due-date based heuristic algorithms, which belong to the same subset. From Table 7, this study concludes that DDHA15 to DDHA20, which are ATC based heuristic algorithms, are the topmost heuristic algorithms among the proposed 20 variants of DDHA for RTS-NMDF-MER.

\section{Conclusions}

A new and very closely related to the real-life scheduling problem of diffusion furnaces: "(Nonidentical multiple diffusion furnaces(NMDF) / machine eligibility restriction (MER), batch, in-compatible job families, dynamic job-arrivals, real time events, non-agreeable release times \& due-dates / Total Weighted Tardiness (TWT)" is considered in this study. Due to the computational difficulties in obtaining optimal solution, particularly for real life-sized problems and considering the advantages of dispatching rule based heuristic algorithms for dynamic scheduling, this study proposed 20 variants of due-date based heuristic algorithms by considering due-date based dispatching rules: EDD, FDD, ODD, MOD, CR, MS, COVERT, ATC and/or BATC for real time scheduling of nonidentical multiple diffusion furnaces with machine eligibility restriction (RTS-NMDF-MER). Based on the analysis of the literature it seems that this is the first study, which compares all possible due-date based heuristic algorithms, particularly for RTSNMDF-MER.

For carrying out the performance evaluation of the proposed 20 variants of DDHA for RTS-NMDFMER, an experimental design has been proposed to generate suitable test data. The absolute performance evaluation of the proposed 20 variants of DDHA, considering 27 problem configurations, (with 10 problem instances per problem configuration) has been carried out empirically by comparing with estimated optimal solution procedure using the standard performance measure: average relative percentage deviation. In addition, the relative performance evaluation has been carried out among the proposed 20 variants of DDHA, statistically using descriptive statistics, randomized block analysis of variance, and Tukey's multiple comparison tests.

Table 5. The results of ANOVA.

\begin{tabular}{|l|c|c|c|c|c|}
\hline Source & Degree of Freedom & Sum of Squares & Mean Square & F-Value & P-Value \\
\hline Variants of DDHA & 19 & $1.1 \mathrm{E}^{+9}$ & $6.2 \mathrm{E}^{+7}$ & 73.383 & 0.000 \\
\hline Block (Instances) & 269 & $1.4 \mathrm{E}^{+10}$ & $5.4 \mathrm{E}^{+7}$ & 64.524 & 0.000 \\
\hline Error & 5111 & $4.3 \mathrm{E}^{+9}$ & $8.4 \mathrm{E}^{+5}$ & & \\
\hline Total & 5400 & $2.9 \mathrm{E}^{+10}$ & & & \\
\hline
\end{tabular}


Rani \& Mathirajan: Real Time Scheduling of Nonidentical Multiple Batch Processors with ...

Table 6. Results of multiple comparisons.

\begin{tabular}{|c|c|c|c|c|c|c|c|c|c|c|c|c|c|c|c|c|c|c|c|}
\hline \multirow[b]{2}{*}{ Proposed DDHA } & \multicolumn{19}{|c|}{ P-values of comparison between proposed 20 variants of DDHA } \\
\hline & $\mid \begin{array}{l}\frac{d}{\Delta} \\
\frac{1}{0} \\
0\end{array}$ & $\begin{array}{l}\stackrel{2}{\Delta} \\
\frac{1}{2}\end{array}$ & $\begin{array}{l}\text { 蓄 } \\
\text { 竞 }\end{array}$ & 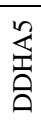 & 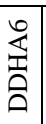 & 离 & 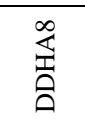 & 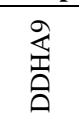 & 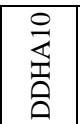 & 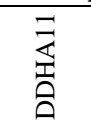 & 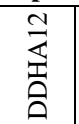 & 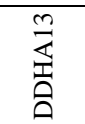 & 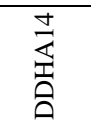 & $\begin{array}{l}n \\
\frac{n}{\Delta} \\
\frac{1}{2} \\
0\end{array}$ & 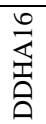 & 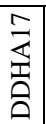 & 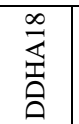 & 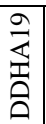 & 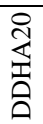 \\
\hline DDHA1 & 0 & 0 & 0 & 1 & 1 & 1 & 0.974 & 0.243 & 1 & 1 & 1 & 1 & 0.004 & 0 & 0 & 0 & 0 & 0 & 0 \\
\hline DDHA2 & & 1 & 1 & 0 & 0 & 0 & 0 & 0 & 0 & 0 & 0 & 0 & 0.72 & 0 & 0 & 0 & 0 & 0 & 0 \\
\hline DDHA3 & & & 1 & 0 & 0 & 0 & 0 & 0 & 0 & 0 & 0 & 0 & 0.72 & 0 & 0 & 0 & 0 & 0 & 0 \\
\hline DDHA4 & & & & 0 & 0 & 0 & 0 & 0 & 0 & 0 & 0 & 0 & 0.72 & 0 & 0 & 0 & 0 & 0 & 0 \\
\hline DDHA5 & & & & & 1 & 1 & 0.974 & 0.243 & 1 & 1 & 1 & 1 & 0.004 & 0 & 0 & 0 & 0 & 0 & 0 \\
\hline DDHA6 & & & & & & 1 & 0.98 & 0.265 & 1 & 1 & 1 & 1 & 0.003 & 0 & 0 & 0 & 0 & 0 & 0 \\
\hline DDHA7 & & & & & & & 0.974 & 0.243 & 1 & 1 & 1 & 1 & 0.004 & 0 & 0 & 0 & 0 & 0 & 0 \\
\hline DDHA8 & & & & & & & & 1 & 1 & 0.974 & 1 & 0.974 & 0 & 0 & 0 & 0 & 0 & 0 & 0 \\
\hline DDHA9 & & & & & & & & & \begin{tabular}{|l|}
0.618 \\
\end{tabular} & 0.243 & 0.632 & 0.243 & 0 & 0 & 0 & 0 & 0 & 0 & 0 \\
\hline DDHA10 & & & & & & & & & & 1 & 1 & 1 & 0 & 0 & 0 & 0 & 0 & 0 & 0 \\
\hline DDHA11 & & & & & & & & & & & 1 & 1 & 0.004 & 0 & 0 & 0 & 0 & 0 & 0 \\
\hline DDHA12 & & & & & & & & & & & & 1 & 0 & 0 & 0 & 0 & 0 & 0 & 0 \\
\hline DDHA13 & & & & & & & & & & & & & 0.004 & 0 & 0 & 0 & 0 & 0 & 0 \\
\hline DDHA14 & & & & & & & & & & & & & & 0 & 0 & 0 & 0 & 0 & 0 \\
\hline DDHA15 & & & & & & & & & & & & & & & 1 & 1 & 1 & 1 & 1 \\
\hline DDHA16 & & & & & & & & & & & & & & & & 1 & 0.993 & 1 & 1 \\
\hline DDHA17 & & & & & & & & & & & & & & & & & 1 & 1 & 1 \\
\hline DDHA18 & & & & & & & & & & & & & & & & & & 1 & 1 \\
\hline DDHA19 & & & & & & & & & & & & & & & & & & & 1 \\
\hline
\end{tabular}

Table 7. Means for groups in homogeneous subsets.

\begin{tabular}{|c|c|c|c|c|}
\hline \multicolumn{5}{|c|}{ Tukey HSD ${ }^{\mathrm{a}, \mathrm{b}}$} \\
\hline \multirow{2}{*}{ Proposed DDHA } & \multirow{2}{*}{$\mathrm{N}$} & \multicolumn{3}{|c|}{ Subset } \\
\hline & & 1 & 2 & 3 \\
\hline DDHA18 & 270 & 617.48 & & \\
\hline DDHA19 & 270 & 645.67 & & \\
\hline DDHA17 & 270 & 645.87 & & \\
\hline DDHA15 & 270 & 686.13 & & \\
\hline DDHA20 & 270 & 712.20 & & \\
\hline DDHA16 & 270 & 739.60 & & \\
\hline DDHA9 & 270 & & 1251.10 & \\
\hline DDHA8 & 270 & & 1349.65 & \\
\hline DDHA12 & 270 & & 1444.16 & \\
\hline DDHA10 & 270 & & 1445.62 & \\
\hline DDHA6 & 270 & & 1483.96 & \\
\hline DDHA7 & 270 & & 1487.00 & \\
\hline DDHA1 & 270 & & 1487.03 & \\
\hline DDHA11 & 270 & & 1487.03 & \\
\hline DDHA13 & 270 & & 1487.03 & \\
\hline DDHA5 & 270 & & 1487.03 & \\
\hline DDHA14 & 270 & & & 1821.18 \\
\hline DDHA2 & 270 & & & 2004.96 \\
\hline DDHA3 & 270 & & & 2004.96 \\
\hline DDHA4 & 270 & & & 2004.96 \\
\hline Sig. & & .993 & .243 & .720 \\
\hline
\end{tabular}


Based on both empirical and statistical analysis, this study concludes that the proposed due-date based heuristic algorithms (that is, DDHA15 to DDHA20), which uses composite dispatching rule, particularly apparent tardiness cost (ATC) rule, for both interrelated decisions: batch formation and batch selection, relatively performs better for RTS-NMDF-MER to minimize TWT. This could be due to the fact that these due-date based heuristic algorithms compute the job priority as well as the batch priority based on the slack time and it leads to avoiding getting high priority for low priority jobs. Furthermore, these efficient due-date based heuristic algorithms would reduce the pressure on meeting the due-date in SM industry within a reasonable computational time and would lead to avoiding the loss of competitive position due to delay in the product delivery. Hence, implementing these types of efficient due-date based heuristic algorithms for bottleneck operation, particularly diffusion operation, which has complex problem characteristics like incompatible job families, nonidentical multiple diffusion furnaces, machine eligibility restriction, dynamic job arrivals, nonagreeable release time and due-date, random occurrence of real time events, would help to improve the performance of semiconductor manufacturing industry.

The benchmark solution procedure: estimated optimal solution procedure has its own limitations. This limitation can be avoided by developing a suitable lower bound method to evaluate the proposed methodologies. Further, during batch construction, this study didn't consider any fixed waiting time for the future arrival of jobs and this makes machine idle. This can be easily addressed in each of the 20 variants of DDHA by defining a fixed waiting time for future arrival jobs for constructing a batch and also to find useful and critical managerial information on the diffusionfurnace's idle time. Further, considering upstream/downstream operation(s) while performing real time scheduling of NMDF-MER would be another future research issue in this area.

Annexure 1. A walkthrough of DDHA1.

\begin{tabular}{|c|c|c|c|c|c|c|c|c|c|c|c|}
\hline \multirow{2}{*}{$\begin{array}{l}\text { Job } \\
\text { J1 }\end{array}$} & \multirow{2}{*}{$\begin{array}{c}\text { Family } \\
\text { f5 }\end{array}$} & \multirow{2}{*}{$\begin{array}{c}\text { Processing Time } \\
20\end{array}$} & \multirow{2}{*}{$\begin{array}{c}\text { Release Time } \\
4\end{array}$} & \multirow{2}{*}{$\begin{array}{c}\text { Due-date } \\
29\end{array}$} & \multirow{2}{*}{$\begin{array}{c}\text { Weight } \\
4\end{array}$} & \multirow{2}{*}{$\begin{array}{l}\text { Job } \\
\text { J14 }\end{array}$} & \multirow{2}{*}{$\begin{array}{c}\text { Family } \\
\mathrm{f} 2\end{array}$} & \multicolumn{3}{|c|}{ Processing Time elease Tim Due-date } & \multirow{2}{*}{$\begin{array}{c}\text { Weight } \\
7\end{array}$} \\
\hline & & & & & & & & 4 & 7 & 21 & \\
\hline $\mathrm{J} 2$ & f1 & 2 & 3 & 18 & 3 & $\mathrm{~J} 15$ & $\mathrm{f} 2$ & 4 & 4 & 8 & 5 \\
\hline $\mathrm{J} 3$ & f1 & 2 & 3 & 20 & 3 & $\mathrm{~J} 16$ & f2 & 4 & 2 & 18 & 9 \\
\hline $\mathrm{J} 4$ & f5 & 20 & 3 & 34 & 7 & $\mathrm{~J} 17$ & f3 & 10 & 1 & 34 & 9 \\
\hline $\mathrm{J} 5$ & $f 4$ & 16 & 2 & 34 & 7 & $\mathrm{~J} 18$ & f3 & 10 & 8 & 30 & 2 \\
\hline $\begin{array}{l}56 \\
17\end{array}$ & f3 & $\frac{10}{4}$ & $\frac{3}{4}$ & $\begin{array}{l}20 \\
21\end{array}$ & $\begin{array}{l}4 \\
5\end{array}$ & $\mathrm{~J} 19$ & f2 & 4 & 5 & 35 & 2 \\
\hline $\mathrm{J} 8$ & $\begin{array}{l}\dagger 2 \\
f 2\end{array}$ & $\begin{array}{l}4 \\
4\end{array}$ & $\begin{array}{l}4 \\
4\end{array}$ & 17 & 10 & $\mathrm{~J} 20$ & f3 & 10 & 4 & 30 & 9 \\
\hline 19 & $\mathrm{f} 2$ & 4 & 7 & 35 & 2 & $J 21$ & f3 & 10 & 8 & 36 & 7 \\
\hline $\mathrm{J} 10$ & f4 & 16 & 1 & 28 & 4 & $J 22$ & f3 & 10 & 2 & 15 & 5 \\
\hline J11 & f4 & 16 & 6 & 27 & 8 & $\mathrm{~J} 23$ & f3 & 10 & 2 & 35 & 3 \\
\hline $\mathrm{J} 12$ & f2 & 4 & 7 & 30 & 9 & $\mathrm{~J} 24$ & f3 & 10 & 7 & 29 & 10 \\
\hline $\mathrm{J} 13$ & f3 & 10 & 7 & 40 & 2 & $\mathrm{~J} 25$ & f3 & 10 & 6 & 22 & 10 \\
\hline
\end{tabular}


Iteration 1

DF DF1 DF2 DF3 DF4

AT $2 \quad 2 \quad 5 \quad 7 \quad 8$

Decision making time: $\mathbf{2}$

Tool failure occur at $\mathbf{2}$ for $\mathbf{2} \mathrm{hr}$ in DF1

DF DF1 DF2 DF3 DF4

AT $\quad 4 \quad 5 \quad 7 \quad 8$

Decision making time: 4

Selected DF: DF1

AT of DF1:4

Capacity of DF1:6

Family 1 (PT:2)

Job RT DD Wt

$\begin{array}{llll}\text { J2 } & 3 & 18 & 3\end{array}$

\begin{tabular}{|c|c|c|c|}
\hline \multicolumn{4}{|c|}{ Family 2 (PT:4) } \\
\hline Job & RT & DD & $\mathbf{W t}$ \\
\hline $\mathrm{J} 15$ & 4 & 8 & 5 \\
\hline J8 & 4 & 17 & 10 \\
\hline J16 & 2 & 18 & 9 \\
\hline J7 & 4 & 21 & J \\
\hline J14 & 7 & 21 & 7 \\
\hline $\mathrm{J} 12$ & 7 & 30 & 9 \\
\hline J19 & 5 & 35 & \\
\hline J9 & 7 & 35 & \\
\hline
\end{tabular}

ST 7

CT 11

WT 15

\begin{tabular}{|c|c|c|c|}
\hline \multicolumn{4}{|c|}{ Family 3 (PT:10) } \\
\hline Job & RT & DD & Wt \\
\hline J17 & 1 & 34 & 9 \\
\hline$J 22$ & 2 & 15 & 5 \\
\hline $\mathrm{J} 23$ & 2 & 35 & 3 \\
\hline J6 & 3 & 20 & 4 \\
\hline $\mathrm{J} 20$ & 4 & 30 & 9 \\
\hline $\mathrm{J} 25$ & 6 & 22 & 10 \\
\hline $\mathrm{J} 24$ & 7 & 29 & 10 \\
\hline J13 & 7 & 40 & 2 \\
\hline $\mathrm{J} 18$ & 8 & 30 & 2 \\
\hline$J 21$ & 8 & 36 & 7 \\
\hline
\end{tabular}

Family 4 (PT:16)

Job RT DD Wt

$\begin{array}{llll}\text { J11 } & 6 & 27 & 8\end{array}$

$\begin{array}{llll}\mathrm{J} 10 & 1 & 28 & 4\end{array}$

$\begin{array}{llll}\text { J5 } & 2 & 34 & 7\end{array}$

ST 6

CT 22

CT 16

WT 5
ST 4

Family 5 (PT:20)

Job RT DD Wt

$\begin{array}{llll}\text { J1 } & 4 & 29 & 4 \\ \text { J4 } & 3 & 34 & 7\end{array}$

CT 24

WT 0

Temporary batch of $\mathbf{f 1}$ has completion time less than the starting time of all other temporary batches. So select it

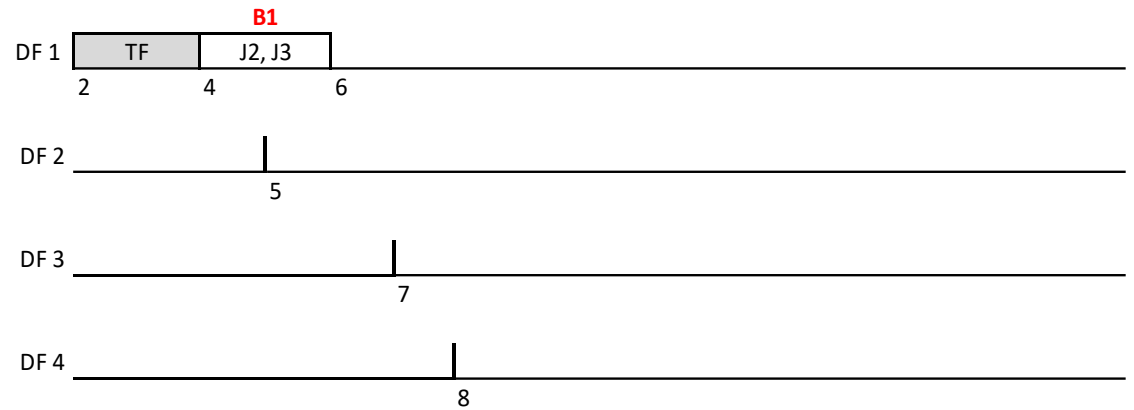




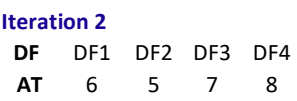

Decision making time: $\mathbf{5}$

Shortage of material occur at 5 for $1 \mathrm{hr}$ in DF2

DF DF1 DF2 DF3 DF4

$\begin{array}{lllll}\text { AT } & 6 & 6 & 7 & 8\end{array}$

Decision making time: 6

Machine breakdown occur at 6 for $4 \mathrm{hr}$ in DF1

$\mathrm{J} 7$ in $\mathrm{f} 2$ weight has been changed into 10

Tool Failure occur at 6 for $1 \mathrm{hr}$ in DF2

DF DF1 DF2 DF3 DF4

$\begin{array}{lllll}\text { AT } & 10 & 7 & 7 & 8\end{array}$

Decision making time: 7

Shortage of material occur at 7 for 2 hr in DF3

DF DF1 DF2 DF3 DF4

$\begin{array}{lllll}\text { AT } & 10 & 7 & 9 & 8\end{array}$

Decision making time: 7

Selected DF: DF2

AT of DF2:7

Capacity of DF2:6

\begin{tabular}{|c|c|c|c|c|c|c|c|}
\hline \multicolumn{4}{|c|}{ Family 1 (PT:2) } & \multicolumn{4}{|c|}{ Family 2 (PT:4) } \\
\hline Job & RT & DD & Wt & Job & RT & DD & Wt \\
\hline & & & & $\mathrm{J} 15$ & 4 & 8 & 5 \\
\hline & & & & $\mathrm{J} 8$ & 4 & 17 & 10 \\
\hline & & & & $\mathrm{J} 16$ & 2 & 18 & 9 \\
\hline & & & & $\mathrm{J7}$ & 4 & 21 & 10 \\
\hline & & & & J14 & 7 & 21 & 7 \\
\hline & & & & $\mathrm{J} 12$ & 7 & 30 & 9 \\
\hline & & & & $\mathrm{J} 19$ & 5 & 35 & 2 \\
\hline & & & & J9 & 7 & 35 & 2 \\
\hline ST & - & & & ST & 7 & & \\
\hline CT & - & & & CT & 11 & & \\
\hline WT & - & & & WT & 15 & & \\
\hline
\end{tabular}

\begin{tabular}{|c|c|c|c|}
\hline \multicolumn{4}{|c|}{ Family 4 (PT:16) } \\
\hline Job & RT & DD & $\mathbf{W t}$ \\
\hline J11 & 6 & 27 & 8 \\
\hline $\mathrm{J} 10$ & 1 & 28 & 4 \\
\hline $\mathrm{J} 5$ & 2 & 34 & 7 \\
\hline
\end{tabular}

ST 7

CT 23

WT 0
Family 5 (PT:20)

Job RT DD Wt

$\begin{array}{llll}\text { J1 } & 4 & 29 & 4 \\ \text { J4 } & 3 & 34 & 7\end{array}$

Temporary batch of $\mathbf{f} \mathbf{2}$ has highest weighted tardiness. So select it

\begin{tabular}{l|l|l|l|}
\cline { 2 - 4 } DF 2 & SM & TF & $\mathrm{J} 15, \mathrm{~J} 8, \mathrm{~J} 16, \mathrm{~J} 7, \mathrm{~J} 14, \mathrm{~J} 12$ \\
\hline 5 & 6 & 7
\end{tabular}

DF 3 SM

DF 4

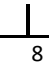


Iteration 3

DF DF1 DF2 DF3 DF4

AT $\quad 10 \quad 11 \quad 9 \quad 8$

Decision making time: $\mathbf{8}$

Operator Illness occur at 8 for 2 hr in DF 4

DF DF1 DF2 DF3 DF4

AT $\quad 10 \quad 11 \quad 9 \quad 10$

Decision making time: 9

$\mathrm{J} 24$ in $\mathrm{f} 3$ due date has been changed into 38

Selected DF: DF3

AT of DF3:9

Capacity of DF3:9

Family 1 (PT:2)

Job RT DD Wt

\begin{tabular}{|c|c|c|c|}
\hline \multicolumn{4}{|c|}{ Family 2 (PT:4) } \\
\hline Job & RT & DD & Wt \\
\hline J19 & 5 & 35 & 2 \\
\hline 19 & 7 & 35 & 2 \\
\hline
\end{tabular}

ST 9

CT 13

WT 0

\begin{tabular}{|c|c|c|c|}
\hline \multicolumn{4}{|c|}{ Family 3 (PT:10) } \\
\hline Job & RT & DD & Wt \\
\hline $\mathrm{J} 22$ & 2 & 15 & 5 \\
\hline J6 & 3 & 20 & 4 \\
\hline J25 & 6 & 22 & 10 \\
\hline $\mathrm{J} 20$ & 4 & 30 & 9 \\
\hline J18 & 8 & 30 & 2 \\
\hline J17 & 1 & 34 & 9 \\
\hline J23 & 2 & 35 & 3 \\
\hline J21 & 8 & 36 & 7 \\
\hline J24 & 7 & 38 & 10 \\
\hline J13 & 7 & 40 & 2 \\
\hline
\end{tabular}

ST 9

CT 19

WT 20
Family 4 (PT:16)

Job RT DD Wt

$\begin{array}{llll}\text { J11 } & 6 & 27 & 8\end{array}$

$\begin{array}{llll}\mathrm{J} 10 & 1 & 28 & 4\end{array}$

$\begin{array}{llll}J 5 & 2 & 34 & 7\end{array}$
Family 5 (PT:20)

Job RT DD Wt

$\begin{array}{llll}\text { J1 } & 4 & 29 & 4\end{array}$

$\begin{array}{llll}\mathrm{J} 4 & 3 & 34 & 7\end{array}$

\begin{tabular}{|c|c|c|c|c|c|c|c|c|}
\hline ST & - & ST & 9 & ST & 9 & ST & 9 & ST \\
\hline CT & - & CT & 13 & $\mathrm{CT}$ & 19 & CT & 25 & $\mathrm{CT}$ \\
\hline WT & - & WT & 0 & WT & 20 & WT & 0 & WT \\
\hline
\end{tabular}

Temporary batch of $\mathbf{f} 3$ has highest weighted tardiness. F3 can process only in DF2. So selected DF as DF2 and capacity as 6 and AT as 11

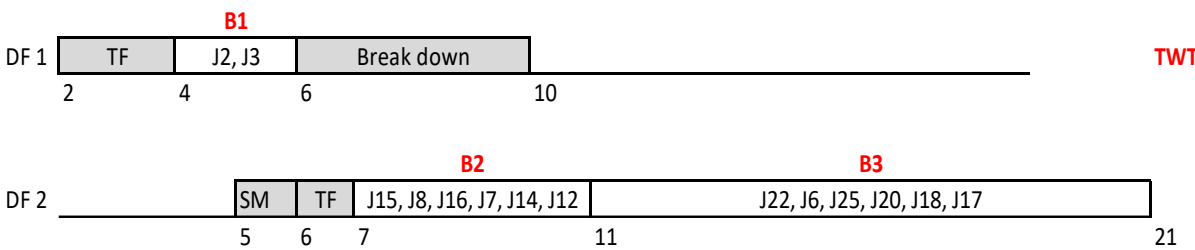

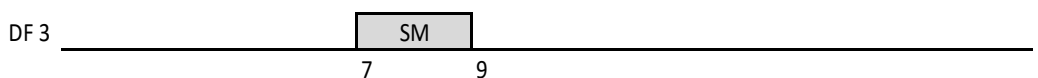

\begin{tabular}{l|l|l|l}
\cline { 3 - 3 } DF 4 & \multicolumn{2}{|c|}{ Ol } & \\
\hline & 8 & 10
\end{tabular} 


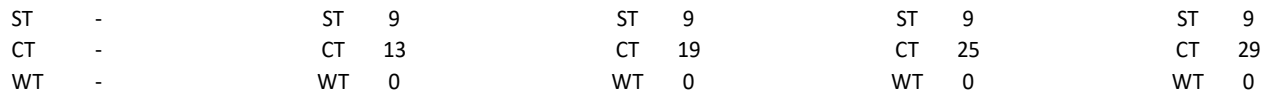

Temporary batch of all family have zero weighted tardiness. So select $\mathbf{f} 2$

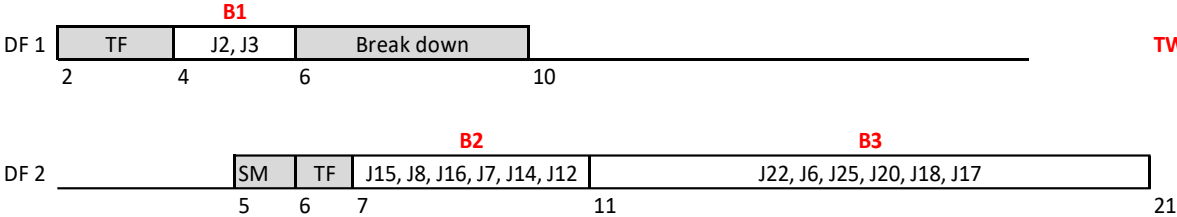

\begin{tabular}{|c|c|c|c|c|}
\hline \multirow[b]{2}{*}{ DF 3} & \multicolumn{3}{|r|}{ B4 } & \\
\hline & SM & & $\mathrm{J} 19, \mathrm{~J} 9$ & \\
\hline & 7 & 9 & & 13 \\
\hline DF 4 & & $\mathrm{OI}$ & & \\
\hline
\end{tabular}


Iteration 5

DF DF1 DF2 DF3 DF4

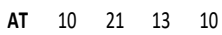

Decision making time: 10

Operator IIIness occur at 10 for $1 \mathrm{hr}$ in DF4

DF DF1 DF2 DF3 DF4

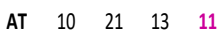

Decision making time: 10

Selected DF: DF1

AT of DF1:10

Capacity of DF1:6

Family 1 (PT:2)

Job RT DD W

Family 2 (PT:4)

Family 3 (PT:10) Job RT DD Wt

Family 4 (PT:16)

Family 5 (PT:20)

$\begin{array}{llllllllllll}\mathrm{J} 21 & 8 & 36 & 7 & \mathrm{~J} 10 & 1 & 28 & 4 & \mathrm{~J} 4 & 3 & 34 & 7\end{array}$

$\begin{array}{llllllll}\mathrm{J} 24 & 7 & 38 & 10 & \mathrm{~J} 5 & 2 & 34 & 7\end{array}$

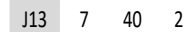

$\begin{array}{llllll}\text { ST } & - & \text { ST } & - & \text { ST } & 10 \\ \text { CT } & - & \text { CT } & - & \text { CT } & 20\end{array}$

$\begin{array}{ll}\text { ST } & 10 \\ \text { CT } & 20\end{array}$

ST 10

CT 26

ST 10

WT

WT -

WT 0

WT 0

CT 30

Temporary batch of $\mathbf{f 5}$ has highest weighted tardiness. So select it

TWT: $53(0+15+34+0+4)$

\begin{tabular}{c|c|c|c|cc|}
\multicolumn{1}{c}{ B1 } & \multicolumn{3}{c}{ B5 } \\
\cline { 2 - 6 } & TF & J2, J3 & Break down & & J1, J4 \\
\hline
\end{tabular}

\begin{tabular}{l|l|l|l|lc|}
\multicolumn{5}{c}{$B 2$} & $B 3$ \\
\cline { 2 - 5 } DF 2 SM & TF & $J 15, J 8, J 16, J 7, J 14, J 12$ & $J 22, J 6, J 25, J 20, J 18, J 17$ \\
\hline
\end{tabular}

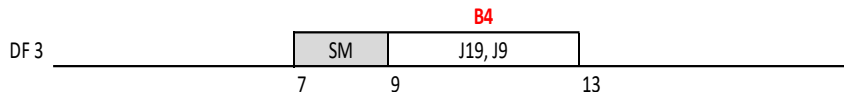

\begin{tabular}{l|l|l|l|}
\cline { 2 - 3 } DF 4 & Ol & Ol & \\
\hline 8 & 10 & 11
\end{tabular} 
Temporary batch of $\mathbf{f} \mathbf{4}$ has highest weighted tardiness. So select it
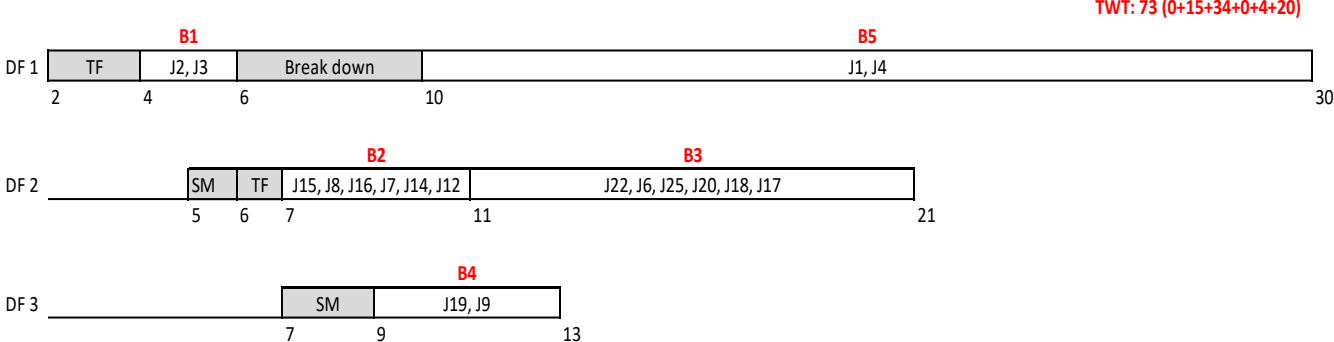

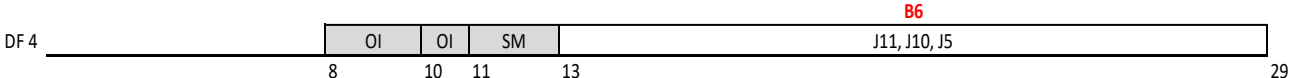


Note: AT: Available time; Wt: Weight;

DF: Diffusion furnace; PT: Processing time; ST: Starting time;
RT: Release time; TF: Tool failure; CT: Completion time;
DD: Due date;

SM: Shortage of material;

WT: Weighted tardiness

\section{Conflict of Interest}

The authors declare that there is no conflict for this publication.

\section{Acknowledgments}

This research did not receive any specific grant from funding agencies in the public, commercial, or not-for-profit sectors. The authors would like to thank the editor and anonymous reviewers for their comments that help improve the quality of this work.

\section{References}

Balasubramanian, H., Monch, L., Fowler, J., \& Pfund, M. (2004). Genetic algorithm based scheduling of parallel batch machines with incompatible job families to minimize total weighted tardiness. International Journal of Production Research, 42(8), 1621-1638.

Baykasoglu, A., \& Ozsoydan, F.B. (2018). Dynamic scheduling of parallel heat treatment furnaces: a case study at a manufacturing system. Journal of Manufacturing Systems, 46, 152-162.

Bilyk, A., Mönch, L., \& Almeder, C. (2014). Scheduling jobs with ready times and precedence constraints on parallel batch machines using meta heuristics. Computers and Industrial Engineering, 78, 175-185. 
Cayo, P., \& Onal, S. (2020). A shifting bottleneck procedure with multiple objectives in a complex manufacturing environment. Production Engineering, 14(2), 177-190.

Cheng, H.C., Chiang, T.C., \& Fu, L.C. (2008, October). A memetic algorithm for parallel batch machine scheduling with incompatible job families and dynamic job arrivals. In 2008 IEEE International Conference on Systems, Man and Cybernetics (pp. 541-546). IEEE. Singapore.

Chiang, T.C., Cheng, H.C., \& Fu, L.C. (2010). A memetic algorithm for minimizing total weighted tardiness on parallel batch machines with incompatible job families and dynamic job arrival. Computers and Operations Research, 37(12), 2257-2269.

Chiang, T.C., Cheng, H.C., \& Fu, L.C. (2008, November). An efficient heuristic for minimizing maximum lateness on parallel batch machines. In 2008 Eighth International Conference on Intelligent Systems Design and Applications (pp. 621-627). IEEE. Kaohsuing, Taiwan.

Reichelt, D., \& Mönch, L. (2006). Multiobjective scheduling of jobs with incompatible families on parallel batch machines. In: Gottlieb, J., \& Raidl, G.R. (eds) Evolutionary Computation in Combinatorial Optimization. EvoCOP 2006. Lecture Notes in Computer Science, vol 3906. Springer, Berlin, Heidelberg, pp. 209-221. https://doi.org/10.1007/11730095_18.

Durasevic, M., \& Jakobović, D. (2018). A survey of dispatching rules for the dynamic unrelated machines environment. Expert Systems with Applications, 113, 555-569.

Emde, S., Polten, L., \& Gendreau, M. (2020). Logic-based benders decomposition for scheduling a batching machine. Computers and Operations Research, 113, 104777. https://doi.org/10.1016/j.cor.2019.104777.

Farhad, T., \& Laya, O. (2007). Development of a set of algorithms for the multi-project scheduling problems. Journal of Industrial and Systems Engineering, 1(1), 23-36.

Fidelis, M.B., \& Arroyo, J.E.C. (2017, October). Meta-heuristic algorithms for scheduling on parallel batch machines with unequal job ready times. In 2017 IEEE International Conference on Systems, Man and Cybernetics (pp. 542-547). IEEE. Banff, Alberta, Canada. https://doi.org/10.1109/SMC.2017.8122662.

Fowler, J.W., Monch, L., \& Ponsignon, T. (2015). Discrete-event simulation for semiconductor wafer fabrication facilities: a tutorial. International Journal of Industrial Engineering, 22(5), 661-682.

Geiger, C.D., \& Uzsoy, R. (2008). Learning effective dispatching rules for batch processor scheduling. International Journal of Production Research, 46(6), 1431-1454.

Geiger, C.D., Uzsoy, R., \& Aytuğ, H. (2006). Rapid modeling and discovery of priority dispatching rules: an autonomous learning approach. Journal of Scheduling, 9, 7-34. https://doi.org/10.1007/s10951-006$5591-8$.

Gokhale, R., \& Mathirajan, M. (2011). Heuristic algorithms for scheduling of a batch processor in automobile gear manufacturing. International Journal of Production Research, 49(10), 2705-2728.

Gokhale, R., \& Mathirajan, M. (2012). A solution framework for a two-stage integrated scheduling problem in automobile gear manufacturing. Indore Management Journal, ORSISOM Special Issue, 1-16.

Graham, R.L., Lawler, E.L., Lenstra, J.K., \& Kan, A.H.G.R. (1979). Optimization and approximation in deterministic sequencing and scheduling: a survey. Annals of Discrete Mathematics, 5, 287-326.

Hosseini, S.M.H., Sana, S.S., \& Rostami, M. (2021). Assembly flow shop scheduling problem considering machine eligibility restrictions and auxiliary resource constraints. International Journal of Systems Science: Operations \& Logistics, 1-17. https://doi.org/10.1080/23302674.2021.1942586.

Jayamohan, M.S., \& Rajendran, C. (2000). New dispatching rules for shop scheduling: a step forward. International Journal of Production Research, 38(3), 563- 586.

Kim, Y.D., Joo, B.J., \& Choi, S.Y. (2010). Scheduling wafer lots on diffusion machines in a semiconductor wafer fabrication facility. IEEE Transactions on Semiconductor Manufacturing, 23(2), 246-254. 
Kurz, M.E. (2003, May). On the structure of optimal schedules for minimizing total weighted tardiness on parallel, batch-processing machines. IIE Annual Conference (pp.1-5). Norcross, USA.

Leachman, R.C. (2002). Competitive semiconductor manufacturing: final report on findings from benchmarking eight-inch, sub-350nm wafer fabrication lines. University of California at Berkeley. (https://microlab.berkeley.edu/csm/\#on-line, accessed on $04^{\text {th }}$ Sept 2021).

Li, D., Wang, J., Qiang, R., \& Chiong, R. (2021). A hybrid differential evolution algorithm for parallel machine scheduling of lace dyeing considering colour families, sequence-dependent setup and machine eligibility. International Journal of Production Research, 59(9), 2722-2738.

Li, L., Fei, Q., \& Pan, G. (2010). ACO-based multi-objective scheduling of identical parallel batch processing machines in semiconductor manufacturing. In: Tauseef, A. (ed) Future Manufacturing Systems. INTECH Open Access Publisher. pp. 163-178.

Li, L., Qiao, F., \& Wu, Q.D. (2009, August). ACO-based scheduling of parallel batch processing machines to minimize the total weighted tardiness. In 2009 IEEE Conference on Automation Science and Engineering (pp. 280-285). IEEE. Bangalore, India. https://doi.org/10.1109/COASE.2009.5234191.

Malve, S., \& Uzsoy, R. (2007). A genetic algorithm for minimizing maximum lateness on parallel identical batch processing machines with dynamic job arrivals and incompatible job families. Computers and Operations Research, 34(10), 3016-3028.

Mathirajan, M., \& Sivakumar, A.I. (2006a). Minimizing total weighted tardiness on heterogeneous batch processing machines with incompatible job families. International Journal of Advanced Manufacturing Technology, 28(9-10), 1038-1047. https://doi.org/10.1007/s00170-004-2452-5.

Mathirajan, M., \& Sivakumar, A.I. (2006b). A literature review, classification and simple meta-analysis on scheduling of batch processors in semiconductor. The International Journal of Advanced Manufacturing Technology, 29(9), 990-1001. https://doi.org/10.1007/s00170-005-2585-1.

Mathirajan, M., Gokhale, R., \& Ramasubramaniam, M. (2014). Modeling of scheduling batch processor in discrete parts manufacturing. In: Ramanathan, U., Ramanathan, R. (eds) Supply Chain Strategies, Issues and Models. Springer Verlag, London. pp.153-192. https://doi.org/10.1007/978-1-4471-5352-8_7.

Mehta, S.V., \& Uzsoy, R. (1998). Minimizing total tardiness on a batch processing machine with incompatible job families. IIE Transactions, 30, 165-178. https://doi.org/10.1023/A:1007466101115.

Mönch, L., \& Roob, S. (2018). A matheuristic framework for batch machine scheduling problems with incompatible job families and regular sum objective. Applied Soft Computing Journal, 68, 835-846.

Mönch, L., Balasubramanian, H., Fowler, J.W., \& Pfund, M.E. (2005). Heuristic scheduling of jobs on parallel batch machines with incompatible job families and unequal ready times. Computers and Operations Research, 32(11), 2731-2750.

Mönch, L., Zimmermann, J., \& Otto, P. (2006). Machine learning techniques for scheduling jobs with incompatible families and unequal ready times on parallel batch machines. Engineering Applications of Artificial Intelligence, 19(3), 235-245.

Morton, T.E., \& Rachamadugu, R.M.V. (1983). Myopic heuristics for the single machine weighted tardiness problem. Pittsburgh, Pa: Carnegie-Mellon University, the Robotics Institute.

Park, H., \& Banerjee, A. (2011, December). A new dynamic scheduling for batch processing systems using stochastic utility evaluation function. In 2011 Winter Simulation Conference (pp. 2302-2314). IEEE. Phoenix, Arizona, USA.

Pinedo, M.L. (2016). Scheduling: theory, algorithms, and systems. Springer Verlag, New York.

Pirovano, G., Ciccullo, F., Pero, M., \& Rossi, T. (2020). Scheduling batches with time constraints in wafer fabrication. International Journal of Operational Research, 37(1), 1-31 
Qi, C. (2006). Closed -loop job release based on WIPLOAD control in semiconductor wafer fabrication, PhD Thesis, School of Mechanical and Aerospace Engineering, Nanyang Technological University. Singapore.

Quadt, D. (2004). Lot-sizing and scheduling for flexible flow lines. Lecture Notes in Economics and Mathematical Systems, (Vol. 546). Springer Verlag, Berlin, Heidelberg.

Rardin, R.L., \& Uzsoy, R. (2001). Experimental evaluation of heuristic optimization algorithms: a tutorial. Journal of Heuristics, 7(3), 261-304.

Rocholl, J., Monch, L., \& Fowler, J. (2020). Bi-criteria parallel batch machine scheduling to minimize total weighted tardiness and electricity cost. Journal of Business Economics, 90(9), 1345-1381.

Rocholl, J., Monch, L., \& Fowler, J.W. (2018, December). Electricity power cost-aware scheduling of jobs on parallel batch processing machines. In 2018 Winter Simulation Conference (pp. 3420-3431). IEEE. Gothenburg, Sweden.

Sarin, S.C., Varadarajan, A., \& Wang, L. (2011). A survey of dispatching rules for operational control in wafer fabrication. Production Planning and Control, 22(1), 4-24.

Uzsoy, R., Lee, C.Y., \& Martin-Vega, L.A. (1992). A review of production planning and scheduling models in the semiconductor industry part I: system characteristics, performance evaluation and production planning. IIE Transactions, 24(4), 47-60.

Vepsalainen, A.P.J., \& Morton, T.E. (1987). Priority rules for job shops with weighted tardiness costs. Management Science, 33(8), 1035-1047. https://doi.org/10.1287/mnsc.33.8.1035.

Vimala Rani, M., \& Mathirajan, M. (2016). Performance evaluation of ATC based greedy heuristic algorithms in scheduling diffusion furnace in wafer fabrication. Journal of Information and Optimization Sciences, 37(5), 717-762.

Yunusoglu, P., \& Topaloglu, Y.S. (2021). Constraint programming approach for multi-resource-constrained unrelated parallel machine scheduling problem with sequence-dependent setup times. International Journal of Production Research, 1-18. https://doi.org/10.1080/00207543.2021.1885068.

Zhou, S., Chen, H., \& Li, X. (2017). Distance matrix based heuristics to minimize makespan of parallel batch processing machines with arbitrary job sizes and release times. Applied Soft Computing, 52, 630-641. 